\title{
Giant Congenital Melanocytic Naevi: review of literature
}

\author{
Nevi Melanocitici Congeniti Giganti: revisione della letteratura
}

\author{
A. Marchesi ${ }^{1}$ F. Leone,${ }^{1}$ L. Sala, ${ }^{1}$ R. Gazzola, ${ }^{1}$ L. Vaienti ${ }^{1}$
}

Key words: congenital naevi, giant neavi, tissue expansion, non surgical treatment

\begin{abstract}
Giant congenital pigmented naevi is a great reconstructive challenge for the pediatric and plastic surgeons. Due to the increased risk of malignant transformation in such lesions, many procedures have been used to remove giant congenital naevi like dermoabrasion, laser treatment or surgical excision combined with reconstruction through skin expansion or skin grafting; among these, only a complete excision can offer an efficacious treatment.

In our centre we use the "tissue expansion" technique in order to achieve a sufficient quantity of normal skin to perform a both staged and radical excision of these giant lesions.
\end{abstract}

\section{Introduction}

Giant congenital melanocytic naevi (GCN) are rare, disfiguring lesions present at birth associated with complications of malignant melanoma and neurocutaneous melanosis. The incidence of giant congenital melanocytic naevi has been estimated at one in 20,000 live births. GCN have been described historically by various nomenclatures, including congenital melanocytic nevi affecting measuring $20 \mathrm{~cm}$ or more in greatest diameter, congenital melanocytic naevi covering more than 1 percent total body surface area in the head and neck region or 2 percent elsewhere in the body or congenital melanocytic nevi greater than $100 \mathrm{~cm}$. The common site is the lower back and thigh area and a very large proportion of the infant's surface area may be involved. GCN shares the pathological characteristics of common nevi and may invade the skin of

Università degli Studi di Milano - I.R.C.C.S. Policlinico San Donato

Indirizzo per la corrispondenza (Corresponding author):

Prof. Luca Vaienti

Via Morandi, n 30 - 20097 San Donato Milanese (Milano)

Email: luca.vaienti@unimi.it

Tel. 02527744567/501 any region of the body. Diagnosis is based on clinical features and pathological examination.

\section{Clinical features}

At birth, congenital naevi $(\mathrm{CN})$ may be very pale macular lesions, which may enlarge, darken and develop terminal hair over a period of years. The rare giant, garment or bathing-trunk naevus is obvious at birth and distressing to parents. During the infant's growth the surface may become rugose or warty and nodules can develop within the giant naevus. The hairy component, which occurs in $95 \%$ of lesions, tends to become more prominent in late childhood.

The relative risk for the development of a melanoma within GCN as reported in the literature varies from 1 to $31 \%$, using seven different definitions. ${ }^{1,2,3}$ Indeed, the highest incidence rate (31\%) were calculated by Reed et al. from a retrospective review of histopathologic materials in an oncology reference centre. The best study involving a large population of patients followed for many years comes from Scandinavia and reports a lifetime incidence of malignant change of $4-6 \%{ }^{4}$ In the literature, the average age at which patients developed a MM was prior to puberty11.1 years. ${ }^{5}$

There may be associated abnormalities such as meningeal involvement, spina bifida or meningocoele when the naevus is over the vertebral column, or club-foot and hypertrophy or atrophy of the deeper structures of a limb. Other hamartomas, such as vascular naevi, lipomas or von Recklinghausen's disease, may be found in patients with extensive congenital pigmented naevi. ${ }^{6}$

Its presence on the head and neck region is usually complicated with neurocutaneous melanosis (NCM), a rare phakomatosis consisting of congenital abnormal pigmentation of the skin and meninges, and neurological features like epilepsy, developmental delay, or focal neurological deficits may be present. ${ }^{7}$ For this reason some authors advise MRI scanning of the central nervous system when the GCN is located on the neck, scalp or medial back. ${ }^{8}$ 


\section{Pathological features}

The pathological features of a congenital melanocytic naevus are the presence of an increased number of melanocytes in the epidermal basal layer in a lentigo-like pattern, a relatively cell-free papillary dermis and aggregates of dermal naevus cells in the lower areas of the dermis not just around but also infiltrating the skin appendages. ${ }^{9}$ The presence of these cells in the skin appendages is

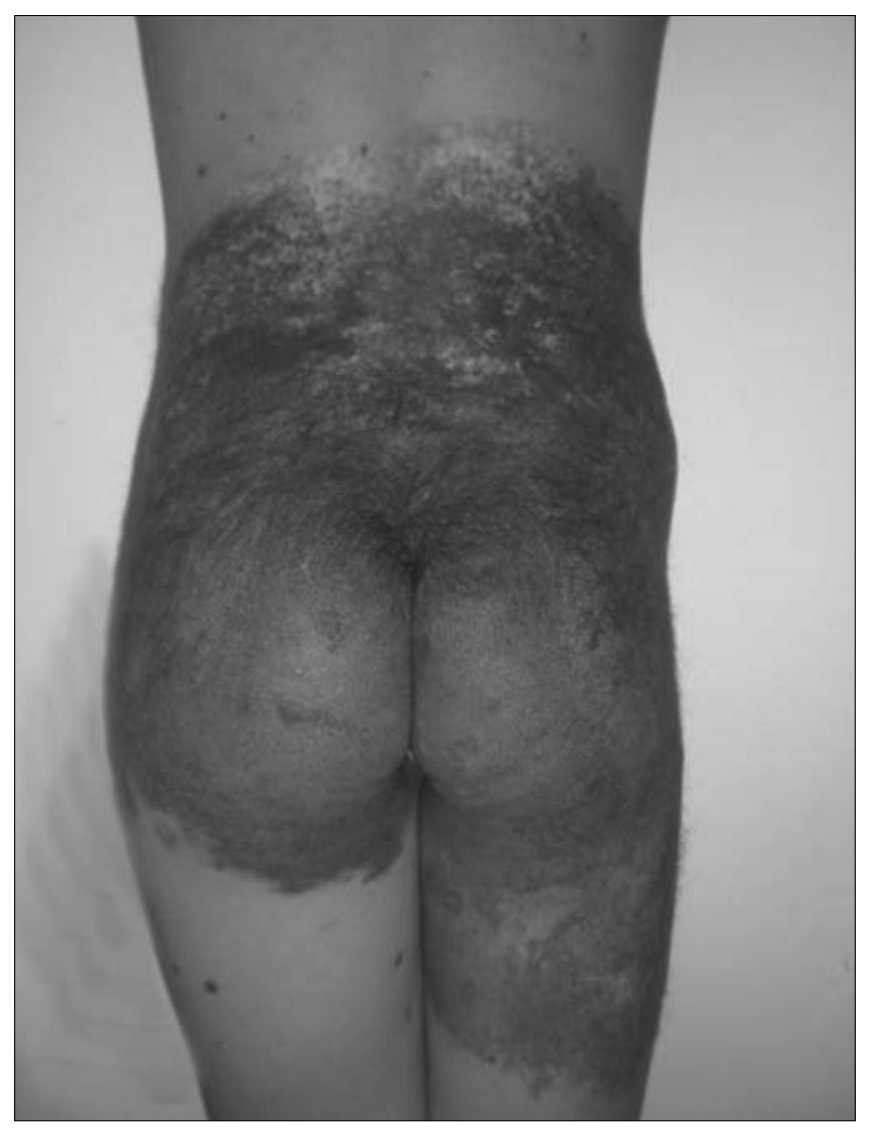

Figure 1.

Example of a giant congenital naevus of the back

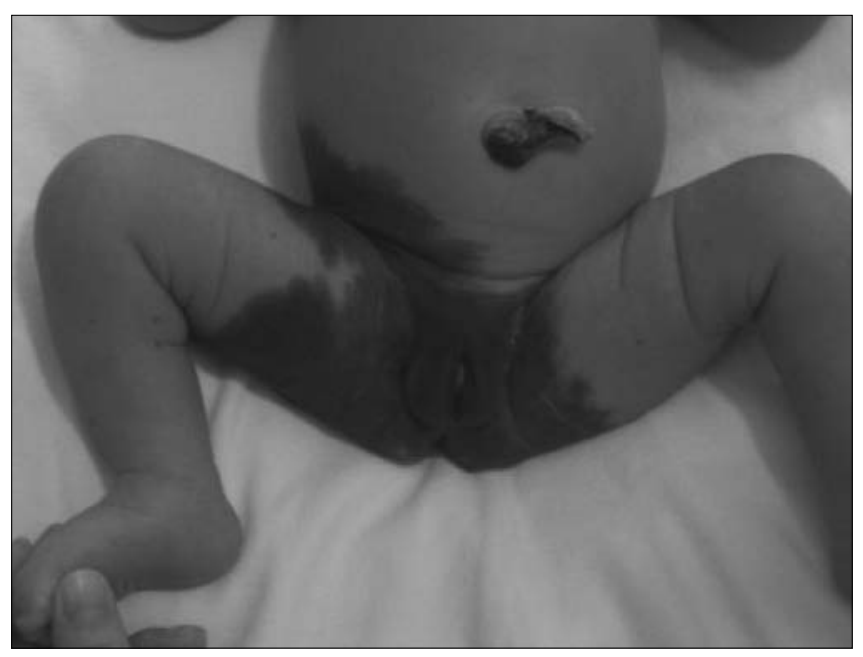

Figure 2.

Example of a giant congenital naevus interesting the genital area a relatively specific feature of congenital naevi. Naevi with a histologically proven junctional component or with neuroneavus elements should be removed in early life, because of a definite premalignant potential. ${ }^{10}$

\section{Reasons for treatment}

Pers reported that $54 \%$ of the GCN patients from his series suffered from significant psychological or emotional distress caused by the naevus. ${ }^{11}$ The establishment of a trusting and open physician - patient relationship is of central importance in this respect. Besides their psychological implications, it has been strongly advocated that GCN should be removed because of their malignant potential. ${ }^{12,13}$

\section{Treatment}

The giant congenital melanocytic naevi represent a challenging surgical problem. Many treatments are performed to prevent malignant melanoma, which can be divided into nonexcisional options (i.e., dermabrasion, laser ablation, curettage, chemical peel) and excisional options (i.e., staged or en bloc excision with primary closure, skin graft, flap, skin substitute, or tissue expansion reconstruction). ${ }^{14}$

\section{Non excisional options}

Shaving of the lesion or deep curettage, initiated by Moss, in the early neonatal period both improve the cosmetic appearance and reduce the risk of development of malignant melanoma by reducing the total number of naevus cells present. There is a tendency, however, for the naevi to repigment, and Zitelli advised against dermabrasion as a treatment for $\mathrm{CN}$, since most of the naevus cells are not removed by this procedure, so that it does not prevent melanoma. Indeed some cases of severe repigmentation after curettage and dermabrasion are described in literature. ${ }^{15}$

Many different lasers have been used for the management of giant congenital melanocytic nevi, including the carbon dioxide, ruby and argon. ${ }^{16,17}$ Horner et al.63 used the carbon dioxide laser in 12 patients in childhood with considerable aesthetic improvement; however, half of their patients developed hypertrophic scarring. L.H. Zaal et al. Goldberg stated that although laser ablation of small CN may achieve satisfactory cosmetic results, persistence of deeper melanocytes limits the usefulness of this treatment. ${ }^{18}$ Moreover several in vitro studies have further concluded that the risk of malignant transformation increases with exposure of melanocytes to laser energy. ${ }^{19,20}$

Phenol chemical peeling was advocated by Hopkins et al. ${ }^{21}$ for congenital melanocytic nevi 
excessively large for excision or lesions for which excision would lead to undesirable scarring. The number of peels required to achieve the treatment outcome of optimal aesthetic appearance, judged by lightening of the pigmentation or resolution of the lesion, was 2.6. Some authors have had less success with chemical peeling, reporting a high rate of scarring and acceptable results in only seven of 17 patients. $^{22}$

\section{Excisional options}

Arons and Hurwitz favored a complete one-stage excision of the $\mathrm{CN}$, including satellite lesions, whenever such surgery is feasible and practical. This procedure should be done especially in the preschool years to minimise the risk of melanoma. Lanier et al. stated that for complete elimination of melanoma risk, the entire naevus must be excised, down to the fascia, because in $\mathrm{CN}$, naevus cells commonly extend into the subcutis and fascia. ${ }^{23}$

Skin substitutes offer several advantages as compared with autogenous tissues, including an absence of donor-site morbidity, a readily available and unlimited supply, and decreased operating room time. However, these materials also have several limitations, including fragility, absence of normal skin properties, decreased survival in a poorly vascularized bed, increased rates of infection, inferior aesthetic outcome, and high cost. Several recent reports have suggested dermal, epidermal, or bilayer skin substitutes for the treatment of tissue defects created from the excision of giant congenital melanocytic nevi. ${ }^{24,25}$ However, results currently achieved with skin substitutes provide inferior form and function compared with reconstruction with expanded flaps from adjacent tissue.

Another valuable technique is the use of tissue expanders, ${ }^{26}$ which was first described by Neumann who published his experience in the reconstruction of a traumatic ear defect in a 52-yearold gentleman by tissue expansion. ${ }^{27}$ The technique consists in placement of a collapsed silicone balloon in a subcutaneous plane and its several expansions over a three-four months period; once the required degree of epidermal expansion is achieved, the normal epidermis is harvested and used as an autologous graft or as a local flap to cover a defect created by the removal of an area of giant melanocytic naevus. This approach has meant that naevi that were previously considered unresectable because of their large surface area can now be removed, frequently by serial excisons, and the resulting defects grafted using the epidermis grown up in vivo using the tissue expanders.

\section{The expanded skin}

In human studies, it does not appear that expander volume or anatomical location has any influence on dermal thickness. There seems to be no histological difference between adults and children undergoing expansion. Light microscopy reveals flattening of the rete ridges as well as epidermal thickening. Skin appendages demonstrate no histological changes during expansion. Capillaries in the papillary dermis are dilated on light microscopy. Electron microscopy reveals longer and thicker elastic fibers and active fibroblasts with an abundance of rough endoplasmic reticulum when compared with normal specimens. ${ }^{28}$ Subcutaneous tissue displays significant fat atrophy with flattening of adipocytes. Muscle under expansion also atrophies and can be replaced by fibrous tissue. Expander capsule thickness does not seem to be related to expander volume, location, or patient age.

\section{Complications of tissue expansion}

Complications have an overall rates in the range of $13 \%$ to $20 \%^{29,30}$ and seem to be greatest in the extremities, particularly in the lower extremities. Major complications are exposure, infections and expander failures, while minor complications are hematoma and seroma.

\section{Discussions}

GCN represents a difficult reconstructive challenge requiring careful preoperative evaluation, staged surgical excision, long patient monitoring and follow-up. With correct treatment, patients and their families may expect a reduced risk of melanoma, amelioration of symptoms, improved aesthetics with associated psychosocial stability, and maintenance of function. We recommend tissue expansion for both radical treatment of giant congenital naevi and good aesthetic result. Because of the intense patient and family cooperation and effort involved in the expansion process, patients and families who are cooperative and compliant are most likely to have a better outcome. Effective education and guidance beginning before surgery and continuing throughout the expansion process are imperative to achieve this outcome.

\section{Bibliografia}

1 DeDavid M, Orlow SJ, Provost N, Marghoob AA, Rao BK, Huang CL, Wasti Q, Kopf A, Bart RS. A study of large congenital melanocytic nevi and associated malignant melanomas: review of cases in the New York University Registry and the world literature. J Am Acad Dermatol 1997; 36: 409-16.

2 Dellon AL, Edelson RL, Chretien PB. Defining the malignant potential of the giant pigmented nevus. Plast Reconstr Surg 1976;57:611-8.

3 Reed WB, Becker Sr SW, Becker Jr SW, Nickel WR. Giant pigmented nevi, melanoma and leptomeningeal melanocytosis. Arch Dermatol 1965;91:100-19.

4 Lorentzen M, Pers M, Brettville Jensen G. The incidence of malignant transformation in giant pigmented naevi. Scand J Plast Reconstr Surg 1977; 11: $163-7$.

5 Zaal LH, Mooi WJ, Sillevis Smitt JH, van der Horst CM. Classification of congenital melanocytic naevi and malignant transformation: a review of the literature. Br J Plast Surg. 2004 Dec;57(8):707-19. 
6 Quaba AA, Wallace AF. Incidence of malignant melanoma arising in large congenital nevocellular nevi. Plast Reconstr Surg 1986; 78: 174-87.

7 Zvulunov A, Esterley N. Neurocutaneous syndromes associated with pigmentary skin lesions. J Am Acad Dermatol 1995; 32: 915-35.

8 Arneja JS, Gosain AKJ. Giant congenital melanocytic nevi of the trunk and an algorithm for treatment. Craniofac Surg. 2005 Sep;16(5):886-93.

9 DeDavid M, Orlow SJ, Provost N, et al. Neurocutaneous melanosis: clinical features of large melanocytic nevi in patients with manifest central nervous system melanosis. J Am Acad Dermatol 1996;35:529-38.

10 Walshe MY, MacKie RM. Histological features of value in differentiating small congenital naevi from acquired naevi. Histopathology 1988; 12: 145-54.

11 Kaplan EN. The risk of malignancy in large congenital nevi. Plast Reconstr Surg 1974;53:421-8.

12 Pers M. Naevus pigmentosus giganticus. Ugekr Laeger 1963; 125:613-9.

13 Arons MS, Hurwitz S. Congenital nevocellular nevus: a review of the treatment controversy and report of 46 cases. Plast Reconstr Surg 1983;72:354-65.

14 Rhodes AR. Melanocytic precursors of cutaneous melanoma: estimated risks and guidelines for management. Med Clin North Am 1986;70:3-37.

15 Arneja JS, Gosain AK. Giant congenital melanocytic nevi. Plast Reconstr Surg. 2009 Jul;124(1 Suppl):1e-13e.

16 Moss AL. Congenital 'giant' naevus: a preliminary report of a new surgical approach. Br J Plast Surg 1987; 40:410-19.

17 Johnson HA. Permanent removal of pigmentation from giant hairy naevi by dermabrasion early in life. Br J Plast Surg 1977; 30: 321-3.

18 Zitelli JA, Grant MG, Abell E, Boyd JB. Histologic patterns of congenital naevocytic nevi, implications for treatment. J Am Acad Dermatol 1984;11:402-9.

19 K. Kishi, N. Matsuda, Y. Kubota, K.-I. Katsube, N. Imanishi, T. Nakajima. Rapid, severe repigmentation of congenital melanocytic. Naevi after curettage and dermabrasion: histological features. $\mathrm{Br}$ J Dermatol. 2007 Jun;156(6):1251-7.

20 Reynolds N, Kenealy J, Mercer N. Carbon dioxide laser dermabrasion for giant congenital melanocytic nevi. Plast Reconstr Surg. 2003;111:2209-2214.
21 Horner BM, El-Muttardi NS, Mayou BJ. Treatment of congenital melanocytic naevi with CO2 laser. Ann Plast Surg. 2005;55:276-280.

22 Goldberg DJ. Benign pigmented lesions of skin: treatment with the Qswitched rubylaser. J Dermatol Surg Oncol 1993; 19:376-9.

23 Chan HH, Xiang L, Leung LC, Tsang KW, Lai KN. In vitro study examining the effect of sublethal QS $775 \mathrm{~nm}$ lasers on the expression of p16INK4a on melanoma cell lines. Lasers Surg Med. 2003;32:88-93.

24 Zhu NW, Perks CM, Burd AR, Holly JM. Changes in the levels of integrin and focal adhesion kinase (FAK) in human melanoma cells following 532 nm laser treatment. Int J Cancer 1999;82:353-358.

25 Hopkins JD, Smith AW, Jackson IT. Adjunctive treatment of congenital pigmented nevi with phenol chemical peel. Plast Reconstr Surg. 2000;105:1-11.

26 Ruiz-Maldonado RR, Tamayo L, Laterza AM, Dura'n C. Giant pigmented nevi: Clinical, histopathologic, and therapeutic considerations. J Pediatr. 1992;120:906-911.

27 Lanier VC, Pickrell KL, Georgiade NG. Congenital giant nevi: clinical and pathological considerations. Plast Reconstr Surg 1976;58:48-54.

28 Abai B, Thayer DO, Glat PM. The use of a dermal regeneration template (Integra) for acute resurfacing and reconstruction of defects created by excision of giant hairy nevi. Plast Reconstr Surg. 2004;114:162-168.

29 Earle SA, Marshall DM. Management of giant congenital nevi with artificial skin substitutes in children. J Craniofac Surg. 2005;16:904-907.

30 Bauer BS, Vicari FA. An approach to excision of congenital giant pigmented nevi in infancy and early childhood. Plast Reconstr Surg 1988; 82: 1012-21.

31 Neumann C. The expansion of an area of skin by progressive distension of a subcutaneous balloon. Plast Reconstr Surg 1957;19:124-130.

32 Pasyk K, Argenta L, Austad ED. Histopathology of human expanded tissue. Clin Plast Surg 1987;14:435-445.

33 Friedman RM, Ingram AE, Rohrich RJ, et al. Risk factors for complications in pediatric tissue expansion. Plast Reconstr Surg 1996;98:1242-1246.

34 Gibstein LA, Abramson DL, Bartlett RA, et al. Tissue expansion in children: a retrospective study of complications. Ann Plast Surg 1997;38:358-364. 